\title{
Study of Emission Rates from Fluidized Catalytic Crackers During Start Up Situations
}

\author{
I.E. Agranovski ${ }^{1}$ and J.M. W hitcombe ${ }^{1}$ \\ 1 Faculty of Environmental Sciences, School of Environmental Engineering, G riffith University, N athan, Brisbane, 4111 - Australia \\ e-mail: i.agranovski@mailbox.gu.edu.au - josh.whitcombe@mailbox.gu.edu.au
}

\begin{abstract}
Résumé - Étude des taux d'émission des unités de crackage catalytique pendant le démarrage Les unités de crackage catalytique (FCCU) sont utilisées depuis de nombreuses années dans l'industrie de raffinage du pétrole. En conditions normales, il y a peu de soucis concernant l'émission dans l'atmosphère de poussière de catalyseur venant de ces procédés. Cependant, au démarrage de l'unité, les taux d'émission sont couramment plus élevés que la normale. Un échantillon d'une souche a été prélevé sur un FCCU durant le démarrage pour confirmer l'ampleur des émissions de particules. Cet article présente les résultats de l'échantillon d'une souche prélevé durant les 19 premiers jours après le démarrage de l'unité et discute les différents régimes de transmission de particules dans l'air, qui ont lieu durant cette période.
\end{abstract}

\begin{abstract}
Study of Emission Rates from Fluidized Catalytic Crackers During Start Up Situations Fluidized Catalytic Cracker Units (FCCU) have been used for many years in the oil refining industry. Under normal operation, there is little concern regarding catalyst dust emission into the atmosphere from these devices. However, concern does arise during FCCU start ups, as higher than normal emission rates are common. Stack sampling was carried out on an FCCU during start up to confirm the magnitude and type of emissions present. The current paper presents the results of stack testing undertaken during the first 19 days after a start up and discusses distinct stages, with regards to air emissions, which occur during that period of time.
\end{abstract}




\section{IN TRO DUCTION}

In recent years, there has been a marked increase in environmental standards concerning air pollution. Recently, several large US oil companies had significant fines imposed on them by the US EPA (Environmental Protection Agency) for breaches of the US Clean Air Act [1]. In addition to stronger enforcement of existing laws, there is a slow shift towards stronger regulation of the emission of fine particles, due to their possible impact on human health [2]. Normally emission rates of $50 \mathrm{mg} / \mathrm{Nm}^{3}$ for existing FCCU's or $30 \mathrm{mg} / \mathrm{Nm}^{3}$ for new units is seen as a standard emission rate set be regulations.

The main sources of particle emissions from an oil refinery are catalyst emissions from Fluidized Catalytic Cracker Units (FCCU). FCCU's have been used in the oil refining industry since their development after World War II. An FCCU is a high-temperature low-pressure system used to convert long-chained hydrocarbons into shorter, more valuable compounds [3]. Under normal operating conditions, catalyst dust emission rates are relatively low and constant, however directly after an FCCU start-up, higher than normal catalyst emissions are likely to occur [4], although only observations or inferences have been made with no direct measurements ever being conducted. The increase in emissions associated with start ups is currently unclear, and needs to be addressed via emission testing.

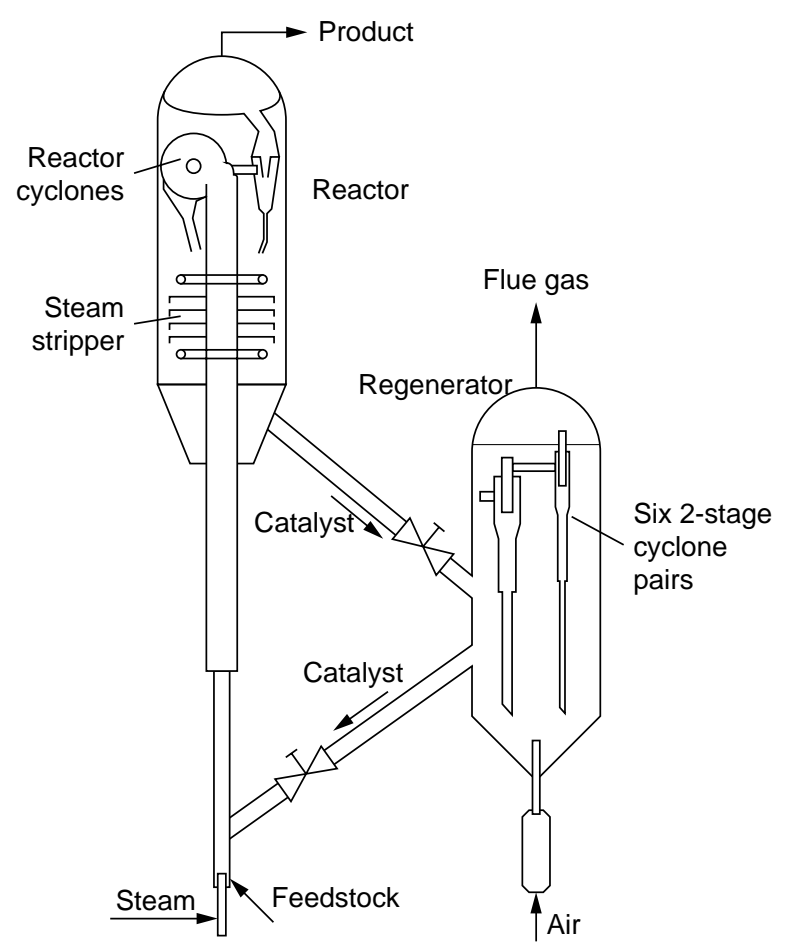

Figure 1

Schematic diagram of the FCCU.
The oil refinery in question was designed in the early 1960's with operations commencing in 1965. The FCCU has a two-stage cyclone configuration for solids removal on the flue gas stream. There are six primary cyclones $(7576 \mathrm{~mm}$ long, $1466 \mathrm{~mm}$ wide) paired with secondary cyclones $(7934 \mathrm{~mm}$ long, $1331 \mathrm{~mm}$ wide) such that the outflow of the primary cyclone feeds directly into the secondary cyclone. All cyclones are positioned vertically with diplegs used to transport the collected catalyst back into the bed. Besides cyclones, no other particle collection device is present, as such the unit can be seen as a non standard unit. There is a $\mathrm{CO}_{2}$ converter used to treat the flue gas before release to the atmosphere. A stylised sketch of the FCCU in question can be seen in Figure 1.

The aim of this paper is to identify the types of emissions experienced during a standard start up operation at the oil refinery, to increase awareness of this phenomenon and promote discussion in the scientific community.

\section{METHODOLOGY AND EQ UIPMENT}

Particle concentration and size distribution monitoring were taken during the first five days of a standard start up operation. Approximately two weeks after the start up, another set of samples was conducted to determine normal running conditions, against which all results could be compared. After the samples were taken, discussions were made with the refinery to confirm that the start up was indeed a 'normal' start up for that facility.

\subsection{Particle Concentration and Sizing}

Air samples were collected from the FCCU stack, $20 \mathrm{~m}$ above the ground, and processed according to published environmental standards and procedures. The US EPA Method 5 [5], "Determination of Particulate Emissions from Stationary Sources" was used as the sampling method to ensure the integrity and comparability of the samples throughout the project's time frame. The sampling equipment was assembled and operated according to the Method 5 requirements; a probe was connected to a filter holder containing an ultra-fine quartz fibre filter. The filter holder was connected to four impingers, the first two containing water, the third being empty and the final containing silica gel. All four impingers were submerged in an ice-bath and attached to a vacuum pump. To ensure isokinetic conditions of sample collection required by US EPA Method 5, the sampling flowrate was monitored by a flowmeter and controlled by an adjustable valve throughout the entire sampling period.

The size distribution of particles in the exhaust gas was determined with the use of an eleven-stage University of Washington Mark 5 Cascade Impactor [6]. Calibration of the 
impactor with that of the gas stream velocity was carried out in order to determine the exact size fractions collected.

Particle size analysis of catalyst taken from the FCCU was undertaken using a Mastersizer S, laser particle size analyser with a small volume sampling handling unit attached (Malvern Instruments, United Kingdom). Filtered water was used to prepare a catalyst suspension required to undertake size distribution tests using the above instrument.

\subsection{Sampling Procedure}

A service platform midway up the length of the stack allowed access to sampling portals across the width of the stack. The stack had four sampling ports, $100 \mathrm{~mm}$ in diameter, allowing a standardized cross-sectional representative sample to be taken, as per requirements of EPA Method 5.

All filters were weighed using a Sartorius balance with a $1 \mu \mathrm{g}$ resolution, then placed in sealed containers to prevent contamination. Equipment required for the sampling tests was calibrated at Griffith University prior to transport and use at the oil refinery.

EPA Method 5 procedures were followed using appropriate apparatus (thermocouple $\pm 1 \mathrm{~K}$, pitot tube $\pm 1 \mathrm{~Pa}$ and absolute filter) to obtain stack parameters and reliability of results [5].

Three types of filters were used during the sampling period. These were impactor's donut-shape filter substrates (Pollution Control Systems Corp., Seattle, WA), an absolute ultra-fine glass fibrous filter (Pollution Control Systems Corp., Seattle, WA), and a ceramic thimble filter (used once for calibration purposes). After each sampling, the probe was withdrawn and the filter changed, ensuring the used filter was placed back into the sealed container to prevent contamination. After all samples were conducted, filters were returned to the laboratory for analysis.

Samples were taken soon after the re-loading of equilibrium catalyst (e-cat—equilibrium catalyst—or used catalyst) into the fluidized bed, with the frequency of samples declining over the start up period as conditions in the fluidized cracker returned to normal. Approximately 2 weeks after start up, the final sample was taken to identify standard operating emission levels, as this was seen as an appropriate time frame according to refinery advice. A sample of the e-cat used during the start up was obtained prior to loading of the FCCU.

\section{RESULTS}

A log particle size distribution (PSD) for the e-cat used during the start up can be seen in Figure 2. The e-cat used during the start up had a narrow PSD with the majority of the particles between $60 \mu \mathrm{m}$ and $120 \mu \mathrm{m}$. It can be seen from the results in Figure 3, that the start up air emissions vary considerably when compared with that of standard ones. Total levels peak at over $900 \mathrm{mg} / \mathrm{Nm}^{3}$ after approximately 2 days from the commencement of start up. This peak level varied considerably from the normal emission level of approximately $70 \mathrm{mg} / \mathrm{Nm}^{3}$. The standard deviation varied between approximately 10 and 15 for all samples. Three samples were conducted at each sampling point, with standard deviations being obtained from the results of each of these tests. Although illustrated in Figure 3, the relatively small magnitude of the variation makes it difficult to see. The Sauter diameter (mean volume-surface diameter) is also plotted on Figure 3 to show the variations during first $450 \mathrm{~h}$ since start up.

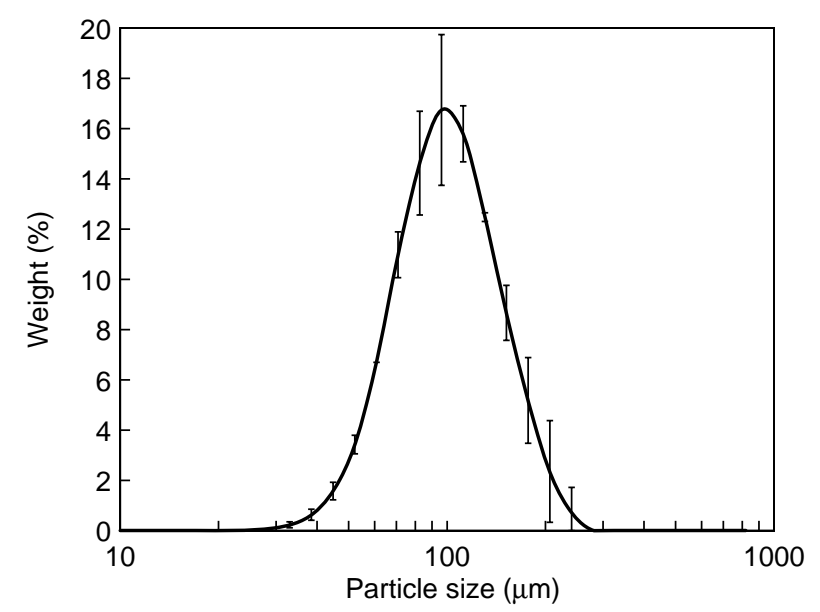

Figure 2

A $\log$ particle size distribution of e-cat used during the start up, including standard deviations.

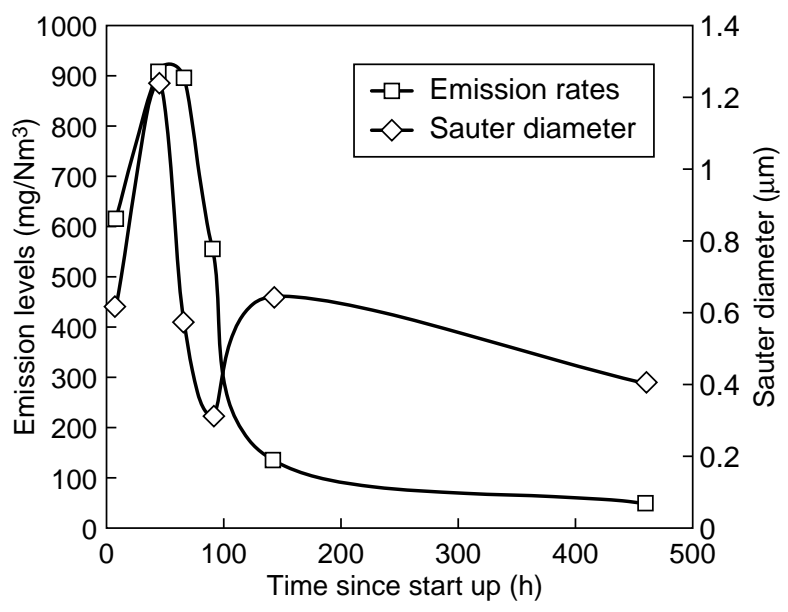

Figure 3

Total emission of catalyst powder over start up period. 


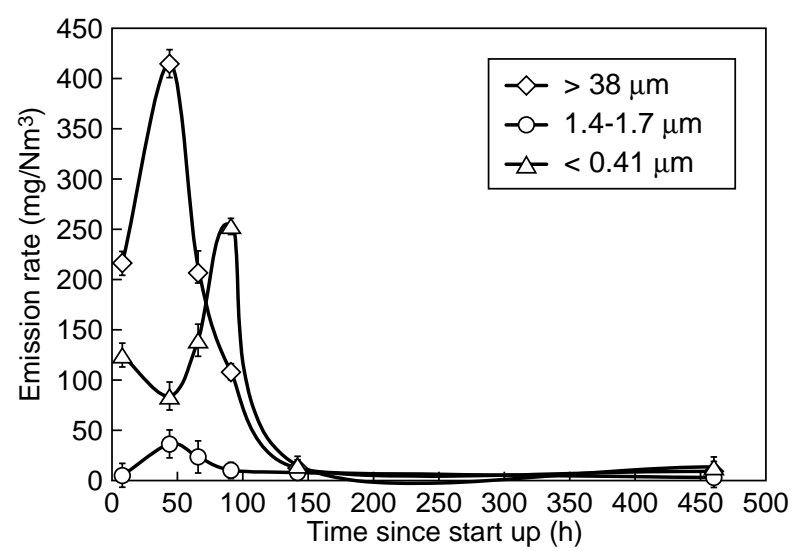

Figure 4

Coarse, mid-sized and fine particle emission rates during start up.

Particle distribution for the start up period can be seen in Figure 4. Only largest, mid-size and finest fractions have been included on the figure to reduce complexity. These size fractions highlight the emission trends present over the start up period. Figure 4 shows how the concentration of particles in the gas stream varies with respect to time and that three stages appear to occur. To allow detailed examination of the start up emissions, test results were separated into pairs and plotted as seen in Figures 5a, 5b and 5c. It must be noted that each figure has a different scale on the $y$-axis. This difference in scale allows the large variation in concentration to be accommodated.

Figure 5a represents the first $44 \mathrm{~h}$ after start up, and it can be seen that the larger size fractions actually increase in concentration, while all others size ranges declined. Taking into account the changed scale, Figure $5 \mathrm{~b}$ indicates that the earlier trend is reversed and the large fraction now decreases in concentration with an increase in the finer fractions. Figure 5c, shows a dramatic drop off in all particle concentrations in the emissions, with higher than normal levels present up to $142 \mathrm{~h}$ after the initial start up.

Stack conditions monitored during the start up are shown in Figure 6. The air temperatures fluctuate over the start up period from an initial low of $578^{\circ} \mathrm{C}$, rising to almost $650^{\circ} \mathrm{C}$ during the $50 \mathrm{~h}$, before falling to $626^{\circ} \mathrm{C}$ at the last sampling time. The change in air temperature is caused by the heating of the catalyst bed, which occurs over this period. The volumetric flow rate stated high at $24 \mathrm{Nm}^{3} / \mathrm{s}$ before reducing to $15 \mathrm{Nm}^{3} / \mathrm{s}$ at the $66 \mathrm{~h}$ after start up. The lower air flow rate at the initial stage of the start up procedure is commonly used for more uniform fluidization of the catalyst in the bed when the thickness of the catalyst layer is below the operational level and because there is less coke to burn off of the catalyst. However, the flow rate increased with grows of the thickness

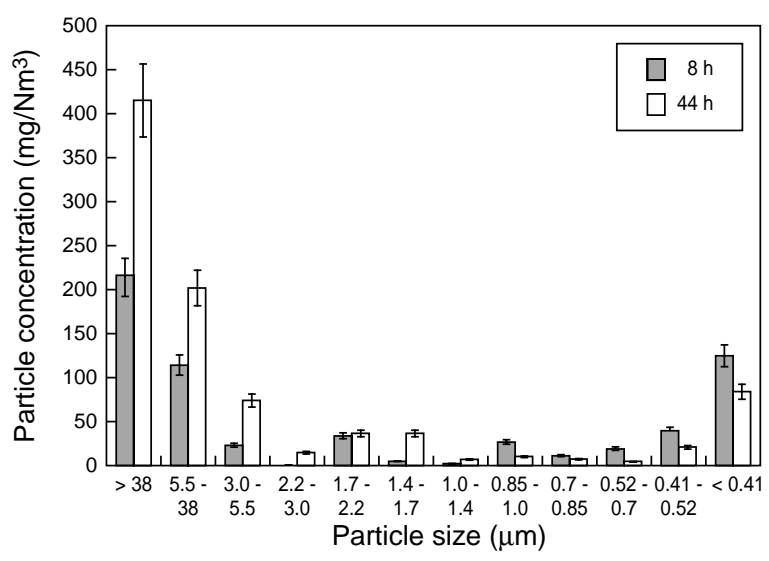

Figure 5a

Emission levels from the FCCU 66 and $91 \mathrm{~h}$ from commencement of operation.

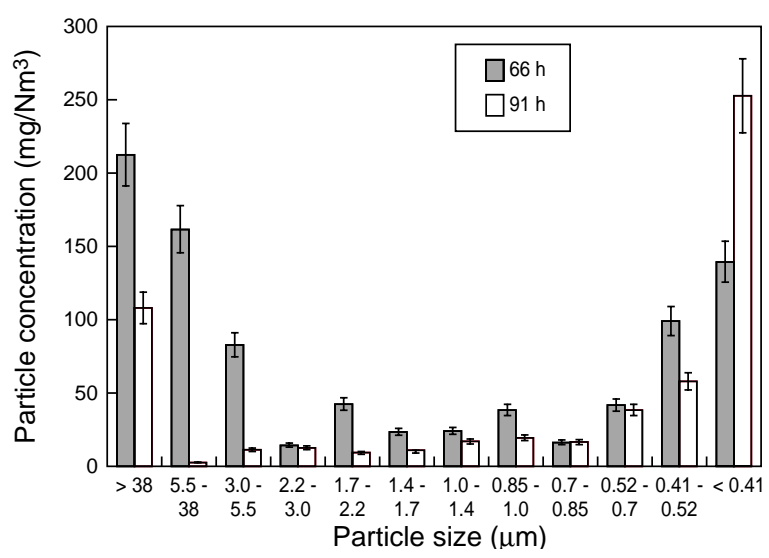

Figure 5b

Emission levels from the FCCU 66 and $91 \mathrm{~h}$ from commencement of operation.

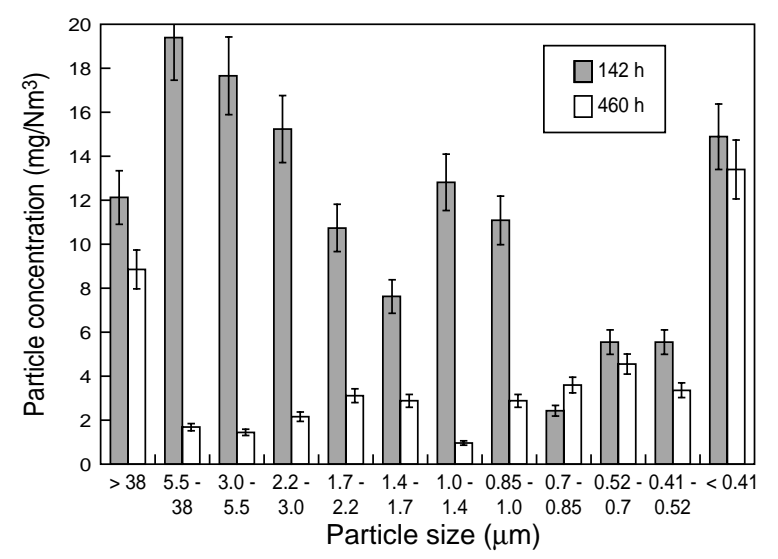

Figure 5c

Emission levels from the FCCU 142 and $460 \mathrm{~h}$ from commencement of operation. 


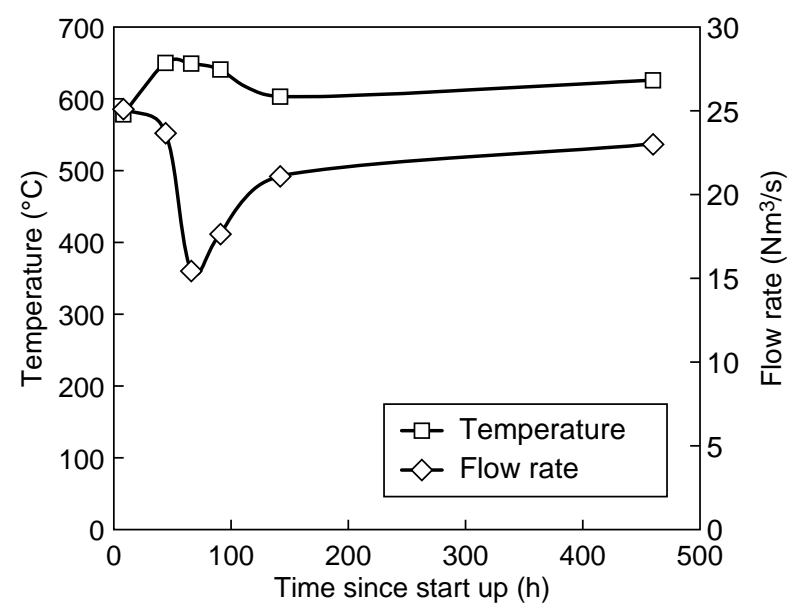

Figure 6

Stack temperature and volumetric flow rate.

of the catalyst layer and reached $25 \mathrm{Nm}^{3} / \mathrm{s}$ at the time when the last sample was taken. Initially the bed is essentially empty of catalyst, with it being rapidly filled to it's normal operational condition of $80 \%$ full, between the period of 50 to $100 \mathrm{~h}$ after the start up.

\section{DISCUSSION}

There is a wide variation between the particle composition found during start up and that of normal operations. Although, it should be noted that all refineries maintain detailed procedures for start ups, however these procedures are designed to minimise operational risks and not specifically tailored to minimise air pollution. As such, no other work has been found dealing with start up emissions from FCCU's and in particular with the types of emissions present. Generally, as outlined by [7], the literature identifies strategies for catalyst loss minimisation under normal operation conditions, not start ups. It is commonly assumed that higher than normal emissions are caused by either dynamic changes in the operating procedures, or direct mechanical failure. These operational changes can influence a wide range of variations of running conditions including cyclone velocities, catalyst attrition rates, failure of dipleg seals and excessive mass flow into the cyclone [8-10]. Three distinct particle distribution patterns were observed during start up.

\subsection{Initial Stage}

Initially, the majority of the emissions comprised of the largest two size fractions (> $38 \mu \mathrm{m}$ and 5.5-38 $\mu \mathrm{m}$ ). As cyclones are inertial separators, their efficiencies increase with the increase in particle size [11]. Therefore, properly operating cyclones should be very efficient at retaining these larger sizes. Without properly operating cyclones, it would be expected that a more even size distribution would be present in the exhaust stream, which is not the case. What causes this failure in the cyclone is not fully understood as flow rates appear to be relatively high during this stage (Fig 5). Increased loading rates in the cyclone should in theory help to increase cyclone efficiency through beneficial particle interaction $[12,13]$, which is not seen in this instance. Although the increase in cyclone loading rates is offset by a decrease in cyclone velocities. As seen in Figure 5, gas flow rates are reduced by almost $10 \mathrm{Nm}^{3} / \mathrm{s}$ during this initial stage of emissions. Another possibility is as the bed level is low, the cyclone diplegs are uncovered which increases the risk of air bypass and particle re-entrainment occurring.

The combination of reduce cyclone velocities and exposed diplegs allows larger particles which are not normally found in the flue gas, to actually be there. With the lack of other start up emission tests in the literature, no comparisons can be made to determine the true normality of this start up. Further consultation with the refinery supports the view that this was a "normal" start up, therefore the fact that these particles are present indicate that there is a general lack of understanding about how start up situations influence catalyst particle emissions.

The second largest emission source is that of the finest size fraction $(<0.41 \mu \mathrm{m})$. From the literature [14, 15], it is commonly accepted that the fine fractions are generated through attrition of larger particles. This theory is supported in the initial sample, as a large amount of coarse material is accompanied by fine material, although there is little of this material in the e-cat. However, the second sample shows a sudden increase in the presence of coarser particles with a subsequent decrease in the finer fraction. Accompanying this is a jump in the mid-size fraction of the emissions.

Also at the first stage, there is a noticeable lack of mid sized fraction, with a slight increase in the second samples. The lack of mid-sized particles $(0.52-5.5 \mu \mathrm{m})$ and the sudden decrease in fines could possibly be explained by the presence of agglomerates early in the start up process, causing the mid-range and fine particles to stick together and be retained in the system. This reduction of the medium and fine size fraction in the emissions seems to support the belief of [16] that there is an attrition/agglomeration process occurring in fluidised beds. As the temperature in the stack increases over this initial period (Fig 6), the influence of this temperature rise in generating this first stage of emission is unclear. As catalyst loading has not started yet, it is unlikely that the reduction of fines in the emissions is due to particle loss in the loading stages.

\subsection{Second Stage}

The second stage of the start up process is defined by a sudden reversal in the particle distribution found during stage 
one. Coarser particles (>38 $\mu \mathrm{m})$ decrease in number whilst the smallest size fraction $(<0.41 \mu \mathrm{m})$ increases dramatically. Again, the middle size fraction, although fluctuating in number, remain relatively low compared with the larger contributors in the stack.

The sudden drop in coarse material with a subsequent rise in fines suggested that the cyclones have started operating correctly. The reduction of coarse material would only be achieved through correct cyclone operations, but as the gas flow rate is actually decreasing during this stage (Fig 6), cyclone efficiencies should be dropping. The increase in fines would be due to attrition, with the products being lost from the system as they are formed $[14,15]$. As the FCCU was utilising e-cat during start up, which should be stronger than fresh catalyst, these excessive attrition rates can not be fully explained. Again, this points to a lack of knowledge regarding how start up situations influence particle characteristics.

\subsection{Third Stage}

Approximately $96 \mathrm{~h}$ after the start up began, the emission levels returned to normal. The concentration of fines $(<0.41$ $\mu \mathrm{m})$ dropped rapidly, indicating a sudden drop in attrition processes in the system. It is also likely that as the catalyst is loaded into the bed, addition attrition occurs in the feed lines, leading to increase fines in the system. As the catalyst bed is at it operational limit at this stage, loading would be halted, reducing the availability of fines in the system. The percentage make up of the emissions still varied considerably from that of normal emissions, suggesting that although the total levels had returned to normal, not all conditions inside the FCCU had.

\section{CONCLUSION}

Observations made by refinery staff as well as brief discussions in the literature have identified the possibility of excessive emission rate occurring over the start up period. These emissions have normally been attributed to one off technical problems. The sampling conducted on a FCCU during a start up situation has quantitatively identified that of excessive emission rates do occur, a previously unstudied phenomena. The sudden change in the particle distribution in the stack during a start up period suggests that there are distinctive stages, with regards to the generation of air emissions, which are not fully explained by hardware operations. At this stage, no clear cause of start up emissions can be identified, only points for discussion. With the apparent lack of knowledge regarding FCCU start ups, with regards to catalyst emissions, no detailed conclusions can be made at this time.

\section{REFEREN CES}

1 Hogue, C. (2000) Two Major Refiners Agree to Cut Air Pollution. Chemical \& Engineering News, 78, 31,12.

2 Johnson, H.J. (2001) The Next Battle Over Clean Air. In Rolling Stone, 48-53.

3 Geldart, D. (1986) Introduction, in Gas Fluidization Technology, D. Geldart, Editor., John Wiley \& Sons: UK, $1-10$.

4 Fletcher, R. (1995) Stepwise Method Determines Source of FCC Catalyst Losses. Oil and Gas Journal, 93, 35.

5 Clark, A.G. (1998) Industrial Air Pollution Monitoring, London, Chapman \& Hill.

6 Pilat, M.J., Ensor, D.S. and Bosch, J.C. (1970) Source Test Cascade Impactor. Atmospheric Environment, 4, 671-679.

7 Salbilla, D.L. (1999) Refiners Have Several Options to Overcome FCCU Opacity Limitations. Oil and Gas Journal, 97, 2.

8 Tenney, E. and Gardner, A. (1998) Fluid Catalytic Cracking Cyclone Design and Modification. Today's Refinery, 23-32.

9 Ezernack, D.D. (1997) Minimize FCCU Startup Problems. Hydrocarbon Processing, 76, 6, 67-72.

10 Tao, Z. (2000) Operational Changes fix FCCU. Oil and Gas Journal, 98, 32, 48-53.

11 Schmidt, P. (1993) Unconventional Cyclone Separators. International Chemical Engineering, 33, 1, 8-17.

12 Fassani, F.L. and Leonardo Jr, G. (2000) A Study of the Effect of High Inlet Solids Loading on a Cyclone Separator Pressure Drop and Collection Efficiency. Powder Technology, 107, 60-65.

13 Ray, M.B., et al. (1997) Post Cyclone (PoC): An Innovative Way to Reduce the Emission of Fines from Industrial Cyclones. Ind. Eng. Chem. Res., 36, 2766-2774.

14 Werther, J. and Reppenhagen, J. (1999) Catalyst Attrition in Fluidized-Bed Systems. AIChE Journal, 45, 9, 2001-2010.

15 Wu, S.Y., Baeyens, J. and Chu, C.Y. (1999) Effect of the Grid-Velocity on Attrition in Gas Fluidized Beds. The Canadian Journal of Chemical Engineering, 77, 738-744.

16 Santana, D., Rodriguez, J.M. and Macias-Machin, A. (1999) Modelling Fluidized Bed Elutriation of Fine Particles. Powder Technology, 106,110-118.

Final manuscript received in September 2002 